\title{
Project Management Tools and Techniques (T\&T) Usage in Building Sector Companies in Cartagena City, T.C.D..
}

\author{
Cárdenas E., Ismael, MSc, Padrón C., Raúl MSc, Universidad Tecnológica de Bolívar, Colombia \\ icardenase@electricaribe.com, rpadron@utb.edu.co
}

\begin{abstract}
This research work was based on an analysis of project management tools and techniques usage and its practical application in the construction sector. It is a fact that projects currently have a high failure rate which was corroborated in this research work through a diagnosis carried out in the city of Cartagena to 22 project managers of important construction companies that currently execute housing projects and therefore, it was determined that techniques and tools of worldwide recognition and suggested by the most relevant standards and methodology are not being used in construction projects. In this work the deficiencies and strengths of the companies were shown when applying the project management techniques and tools; a guide was prepared to use them through specific recommendations to the construction sector.
\end{abstract}

Keywords- Construction, Techniques, Tools.

\section{INTRODUCTION}

According to the PMBOK guide [1] project management is the application of knowledge, skills, tools and techniques to project activities in order to meet project requirements. Tools and techniques are the basis upon projects management are built as discipline; once these tools are mastered and properly used the companies that make projects take the next step towards the use of solid methodologies, standardization and implementation of good practices, implementation of PMO project office and the search for organizational maturity. This research work was mainly focused on good practices related to Tools and Techniques T\&T useful in project management. In essence, the theoretical framework is shown in a general way, starting with the strategic framework of project management, life cycle, types of organizations and the main tools and techniques taken into account during the initiation, planning, execution, monitoring and control and closure. One of the main products of this research was the design of a data collection instrument that can not only be applicable to the construction sector, but serves as a basis for making diagnoses in other areas or sectors where projects are executed. The diagnosis could show at what level is each tool and technique of project management used in the construction companies of Cartagena city. From this analysis it was possible to conclude that a group of tools and techniques are used optimally and others are not thus their potential is not exploit for the organization benefit. From the results of the research and according to the vocation and needs of the sector, a prioritization of T\&T was made, especially, those impacting

Digital Object Identifier (DOI):

http://dx.doi.org/10.18687/LACCEI2019.1.1.153

ISBN: 978-0-9993443-6-1 ISSN: 2414-6390 the most the results of the projects of the construction sector. To facilitate and train on its use a didactic guide was designed recommending the relevance of T\&T taking into account the findings of the sector and the main worldwide references.

\section{BACKGROUND}

The building activity in Cartagena is divided into two main branches: construction, mainly housing, and civil infrastructure works, both for the public and private sectors. The activity is complemented with companies that are indirectly related to construction, such as brick kilns, cement factories, finished wood, paint, steel, etc.

[2] Construction behavior sector presents cycles of expansion and contraction directly related, among other factors, to the product demand, the interest rates of the financial market, the availability of financial resources and the policies current government implements, those that generally respond to the incentive of employment generation.

A large number of residential, commercial and industrial construction projects are currently being carried out in Cartagena. The construction promoter companies, as well as contractors and subcontractors, execute projects on a daily basis using basic methodologies or procedures of their organizations. According to information provided by [2], the project launches as of September 2016 increased by $21.8 \%$ respecting of the immediately previous year, measured in housing units.

Companies do not have methodologies based on international standards such as PRINCE2, APM, PMI, P2M or IPMA. It is well known that projects have a high rate of failures, because they do not comply with the execution times, approved budgets and expected scope; regarding this the PMI project managers, programs and portfolios worldwide survey [3] shows that $71 \%$ of the projects meet the objectives when the project management culture is of high priority in the companies. The figure is even worse when the culture of project management is of low priority reaching $52 \%$.

It is clear then that the projects are not successful in general terms, mainly due to the existing lack of knowledge in project management within the companies, and low level of application of the methodologies of project management and tools and techniques. This is corroborated with the survey carried out in Cartagena for housing construction companies in which it is determined that projects constantly fail as follows: from 22 Project Managers surveyed, $13.64 \%$ consider that their projects 
comply in terms of schedule, scope and budget up to $50 \%$ of the time, $50 \%$ state that their projects are successful between $50 \%$ and $80 \%$ of the time and only $36.36 \%$ of Project Managers indicate that their projects fully comply with the triple restriction between $80 \%$ and $100 \%$ of the times they execute their projects.

This is a quantitative research, supported by survey techniques and structured questionnaires in order to determine the use of project management tools and techniques in the construction companies of Cartagena city.

The units of observation were the housing construction companies formally and legally registered in Cartagena. It is a finite population, constituted by 109 housing construction companies registered in CAMACOL. This information is complemented with the projects registered in the domiciliary public utility companies obtaining a total of 120 companies that constitute the target population of the research work. For the purpose of the study a random sample of 22 companies was selected. The procedure for processing the information is described below:

- Information Supply: Construction companies officials; Construction Managers, Project Managers, Engineers, Resident Architects.

- Collection instruments: Surveys, Meetings.

- Processing techniques: results tabulation, digital files.

- Information organization: Sorting tables, software and tabulation.

- Analysis and interpretation: Graphics, synthesis, descriptive analysis.

\section{MATERIALS AND METHODS}

As defined [4], project management is a formal discipline of business management through which projects are planned and executed following a systematic, repetitive and scalable process. Project management is the process of creating essential and systematic data on results, time and resources, in order to maximize the effectiveness of each decision derived from a compensatory balance. On the other hand for [5], project management consists of the application of processes, methods, knowledge, skills and experience to achieve the project's objectives. Likewise, it is defined as the planning, organization, coordination, direction and control of resources to achieve the objective of the project. For [6] the project management process involves planning the work and, subsequently, working on the plan. A fourth definition is established by the Project Management Institute PMI [1], as the knowledge application, skills, tools and techniques to project activities in order to meet the project requirements. This last definition, highlights the tools and techniques as essential for the achievement of objectives. The state of the art of this research seeks to inventory and rescue that cumulus of knowledge that has been developed over the last decades and that are considered good practices for the effective projects management. Fig. 1 [7] shows the research contribution in project management in the last five decades and the main tools and techniques developed. In its evolution it is observed that much before the Gantt diagram, the engineers of projects had been consolidating the discipline, but its vertiginous development is marked in the last 30 years with more recent developments with agile methodologies, performance and government among others.

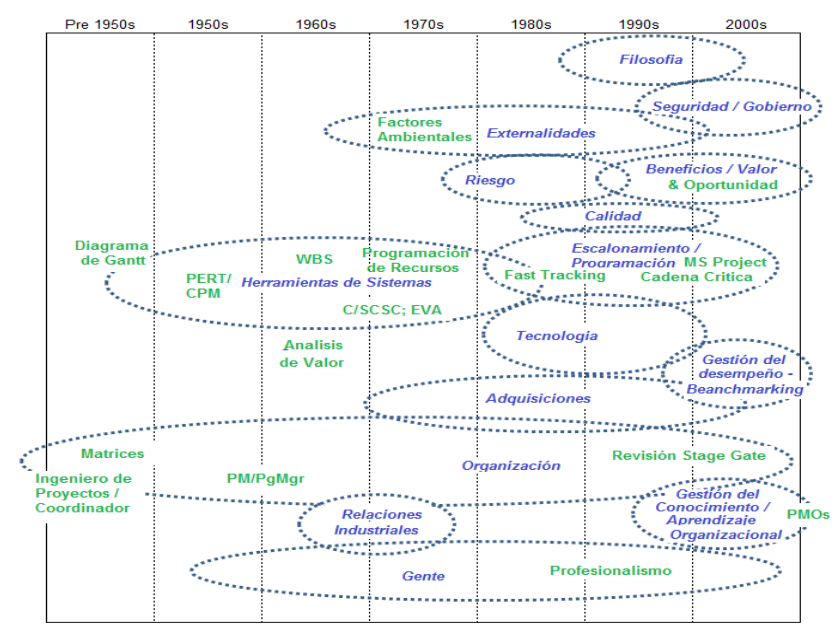

Fig 1. PM-related research contribution over the past five or more decades Source: International Journal of Managing Projects in Business Vol. 3 No. 1, 2010.

The above information is also addressed and corroborated by other authors such as [4], in which it describes a contribution to the T\&T such as the input of Frederick Taylor with his scientific study of the work, as well as the graphics methodology developed by Henry Gantt, PERT and other processes that gave impetus to project management.

\section{A. Strategic framework for project management}

All organizations have a Strategy; formal or informal, all have an objective about where and how they want to be in the future. Every day companies learn how to use Tools and Techniques for Strategic Planning.

Strategic Planning is defined by [8] as the art and science of formulating, implementing and evaluating multidisciplinary decisions that allow a company to achieve its objectives. The objective is to integrate administration, marketing, finance, accounting, production, operations, research and development and information systems in order to implement and execute the strategy and achieve the success of an organization.

In the same sense, for [9] strategic planning is the process of formulating and implementing decisions about the future direction of an organization. This exercise is crucial for any organization survival because it is the process by which the organization adapts to its ever changing environment and is applicable to all levels of management and all types of organizations.

The projects are the materialization of the strategic plans. Once the plans to reach the strategy are defined, projects are formulated and evaluated. In this sense it is important to detail T\&T to formulate, evaluate and select projects framed in the organizational strategy of the companies. Likewise, mental maps are useful, a fundamental tool for decision making.

\section{B. Projects and Organizational Strategy}


In [8], strategic planning model is a clear and practical method for formulating, implementing and evaluating strategies and consists of the following stages: developing the vision and mission statement, establishing the long-term objectives, generating, evaluating, selecting and implementing strategies, measure and evaluate performance.

[10] complements the sequence of [8] with the projects world and states that the stages of strategic planning are the following: Review and define the mission of the company, establish long-term goals and objectives, analyze and formulate strategies to achieve objectives, carry out strategies through the projects.

In this sense, projects are the basis and the core of the strategies; it is at this point that projects are first devised. The projects are born as the answer to the fulfillment of the longterm objectives of the organization.

In this context, [10] establishes that strategies implantation is the most difficult step and that the strategies are carried out through projects through a hierarchical process so that scarce resources are allocated and finally the project is managed.

For [10], a project is a complex, non-routine, limited by time, budget, resources and performance specifications and designed to meet the client's needs effort. Its main characteristics are: they have an established objective, a life cycle defined with a beginning and an end, involves several departments and professionals, different jobs, and has specific requirements of time, cost and performance.

There are many complementary definitions dating from the 90's such as: [11] A project is a unique initiative with a beginning and an end, carried out by people to achieve the goals established within the cost parameters, term and quality; [12] A project is an organized work to achieve a predefined goal or objective that requires resources and effort, it is a unique undertaking that has a budget and a schedule.

The Project Management Institute presents a general definition of what a project represents: [1] A project is a temporary effort undertaken to create a unique product or service.

For [13] it is clear then that projects allow organizations to implement their business strategies. They are the main way that companies operationalize their corporate objectives.

\section{Start of Projects}

It is important to ensure that all projects are coordinated with the strategic goals and that they are prioritized in an appropriate manner, which is achieved through portfolios management.

Portfolio management provides information that allows the company to make the best business decisions. As projects that require funds and people generally exceed the resources available, it is important to follow a logical and defined process to select the projects to be executed. [10] It states that the design of a project portfolio system must include the classification of a project, selection criteria dependent on classification, sources of the proposals, the evaluation of these and management of the project portfolio.
The companies have three types of projects in their portfolios: Compliance and Emergency, Operational and Strategic.

A project must enter the portfolio as long as it has strategic value. Compliance projects ignore selection criteria and should be executed for the company continuity. The rest of the projects are prioritized according to company's strategy.

Organizations must establish their own project selection and prioritization model, taking into account both financial and qualitative criteria.

Companies must publish rating model and make it available to the entire company in order to give credibility and discipline to that selection. This classification gives project managers an understanding of how their project contributes to the organization goals and how it is located compared to other projects.

[1] proposes T\&T to start the Project charter and defines it as the document that formally authorizes the existence of a project and gives the project manager authority to assign the organization's resources to project activities. Therefore, project prioritization models and charter project are important $\mathrm{T} \& \mathrm{~T}$ for projects initiation.

\section{Project Planning}

For [14] the scope statement is the project management heart, since it reflects the best efforts of a project team to create the documentation and approve project important parameters before proceeding to development stage.

Pinto [13] proposes some key steps to make the scope statement: Establish project goal criteria; Develop Project Management Plan; Establish a work breakdown structure WBS - and Create the scope baseline.

[10] One of the most important project manager tasks is to handle changes that occur in time, cost and scope. To achieve this, project nature and priorities must be defined and understood. An useful technique to achieve the above is to establish project matrix priorities to identify which criterias are limited, which should be highlighted and which ones should be accepted.

In Fig. 2 [10], an example of a priority matrix for a generic project is observed.

\begin{tabular}{|l|c|c|c|}
\hline & Time & Scope & Cost \\
\hline Limit & & $\mathrm{x}$ & \\
\hline Underline & $\mathrm{x}$ & & \\
\hline Accept & & & $\mathrm{x}$ \\
\hline
\end{tabular}

Fig. 2. Priorities Matrix

Source: Adapted from Gray \& Larson, 2015. Chapter 4

In the priority matrix, "Limit" refers to parameter being fixed, in this case, the scope is unmodifiable. Likewise, "Underline" refers to taking advantage of opportunities, in this case, to shorten the schedule. And finally, "Accept" corresponds to the parameter that can be exceeded, in this example, the budget. This priorities matrix must be established from the beginning of the project with the client and sponsor, so that later 
in the project when changes arise, decisions are made based on these hierarchical criteria.

[1] A work breakdown structure (WBS) is a group oriented to the project elements delivery that organizes and defines total project scope. Each descending level represents an increasingly detailed definition of a component of the project. Likewise, for [15] the EDT establishes project scope by dividing its general mission into a cohesive set of increasingly specific synchronized tasks.

According to [13], the WBS has six main purposes: It enhances project objectives; it is the project organization chart; creates the logic of tracking costs, time, and performance; it can be used to communicate the project status; it can be used to improve the project global communications; It shows how the project will be contracted.

The technique used to carry out the WBS is the decomposition into which the project scope and deliverables are divided and subdivided into smaller and more manageable parts. [1] The work package is the work defined at the lowest level of the WBS for which cost and duration can be estimated and managed.

The WBS must be accompanied by a dictionary (WBS Dictionary) in which the information on the deliverables, activities and programming of each of the WBS components is recorded. [1] Considers that dictionary may include: ID, work description, assumptions and restrictions, milestones, resources, costs, quality and quality requirements and acceptance criteria, among others.

For [10] it is important the WBS integration to the organization, the structure of organization decomposition (SOD) and is not more than the way in which the company has been organized to discharge responsibility of the tasks and in such sense WBS is used to relate organizational units responsible for carrying out the work.

The WBS is so important as a tool in projects management that has been embodied in different international standards and methodologies, such as the PMI, IPMA, APM, etc., and in some cases texts have been published exclusively dedicated to studying the WBS in which the benefits of that tool are developed more widely.

Several studies highlight [16] that in order to add value to project performance and help success, the project chain approach inspired by supply chain thinking in the manufacturing sector is introduced and uses three types of decisions: authorization, selection, and plan decision. A primitive element of decision is defined when all three types of decisions can be coupled. Each task in the primitive element can itself contain subtasks that in turn will comprise new elements. The primitive elements are nested together in a chain of project decisions.

\section{E. Projects Execution}

One of the most important techniques during the projects execution are the meetings, since through them [1] it raises that project focus is analyzed, the way in which the work will be executed to achieve the project objectives and the way how the project will be monitored and controlled. According to [1], meetings are of three types: exchange of information, brainstorming or decision-making. Meeting attendees can include the project manager, the team, and some stakeholders such as subcontractors, suppliers, etc. Each attendee must have a pre-established role so that they can actively participate.

The meetings are prepared with a clear agenda and a specific objective. Minutes must be taken of these meetings and a list of actions to be taken or commitments made. There are face-to-face and virtual type meetings.

According to [1], another important tool during the project execution is the information system for project management (PMIS), which is part of the company's environmental factors. This system must have programming tools, work authorization system, configuration management system, information collection and distribution system.

The (PMIS) generally acquired by organizations as software packages are designed to provide managers with the necessary decision support in the planning, organization and control of projects. However, the actual contribution of PMIS to the project success or performance has been little studied. In the study carried out in [17], the quality of PMIS currently used in organizations was evaluated empirically and examined its impact on project managers and project performance, based on a successful PMIS model.

This model is made up of five constructs: PMIS quality, PMIS information quality, the use of PMIS, the individual impacts of PMIS and the impacts of PMIS on project success. The data analysis confirms the important contribution of PMIS to the project management success. In this sense, improvements were observed in management tasks efficiency and effectiveness in terms of better planning, programming, monitoring and control of the project. There were also improvements in terms of more timely decision making. The advantages obtained from the use of the PMIS are not limited to individual performance, but also include the project performance. These systems had direct impacts on the projects success, since they contribute to improve budgetary control and meet project deadlines, as well as comply with technical specifications.

The project management plan must have a communications matrix, which is used mainly in the group of processes for the project execution. It is in the execution where it is clearly required that communication channels are established, so the communication matrix resulting from communications plan is mandatory in order to execute the projects in an optimal manner.

The communications plan mitigates project problems and ensures that clients, team members and other stakeholders have the necessary information to perform their jobs. For [13] the purpose of a communications plan is to express what, who, how and when the information will be transmitted to project stakeholders, in such a way that it is possible to trace the programs, problems and actions.

The team building is another important aspect in the projects execution. While there are many organizational theories around team building, there is no single standardized criterion for doing this work. This is corroborated by [13] that in his study he challenged the validity of a standard team development model, since he observed that the teams evolution 
process in projects is quite different. However, it is important to mention the team-building model, for this purpose, [18] it establishes that the groups go through several easily identifiable stages of maturation and that they are usually found in a variety of organizations that include groups formed for a variety of purposes.

[19]states that although project teams are commonly used within organizations at the execution stage and have been widely studied, there is still no consensus on how to define success in the project team and what are the factors contributing the most to it. In the research, [19] sought to develop an initial and integral project team model using a diverse sample of 133 teams, and using regression analysis and structural modeling. Effectiveness, efficiency and innovation were the main technical performance dimensions. Support for management, cooperation and communication were positively related to effectiveness; efficiency was positively related to clarity of objectives, cooperation and team harmony, but negatively related to team diversity; and innovation was positively associated with knowledge / skill and cohesion, but negatively associated with team harmony.

The state of the art makes it clear that the meetings, the PMIS, the communications matrix and the formation and development of teams T\&T are important for the execution phase.

\section{F. Project Control}

The Gantt chart is a graphical tool whose objective is to expose the expected dedication time for different tasks or activities over a given total time. Despite this, the Gantt chart does not indicate the relationships between activities. In 1896, Karol Adamiecki invented a new medium of interdependent processes that are presented in order to improve the visibility of production programs. With minor modifications, Adamiecki's letter is now more commonly known as the Gantt chart. Given the position of each task over time makes it possible to identify relationships and interdependencies.

Since its introduction, Gantt diagrams have become a basic tool in the projects management of all kinds, in order to represent the different phases, tasks and activities programmed as part of a project or to show a timeline in the different activities making the method more efficient.

The Milestones Diagram is a simple tool for a project plan development graphic representation. It consists of a table that relates the milestones with the start and / or end date of them. This technique has the advantages of simplicity and ease of preparation. And as a disadvantage, it does not reflect the interrelationships between the different activities, generating uncertainty. The milestone diagram is used to summarize project calendars. It is a basic technique next to the Gantt diagram.

But when the need to plan and control complex projects arises, other techniques such as those based on CPM precedence networks, PERT diagrams and the critical chain are also required. These networks relate the activities so that the project critical path can be visualized and allow to reflect a time scale to facilitate the allocation of resources and the determination of the budget. The Gantt chart, however, is useful for the relationship between time and workload.

The " $\mathrm{S}$ " curve is a tool that helps to know, control and apply the necessary corrections. This curve represents in a project the real progress respecting to the planned in a cumulative period to date. The curve is called " $\mathrm{S}$ " because of its shape. Normally, at the beginning of the project there is a trend of increasing accumulated costs, while these accumulated costs decrease towards the end. The first version of Curve $\mathrm{S}$ is created based on the current schedule and the initial budget. Later it can be updated as new versions are created. The objective is to detect existing deviations and take measures to correct them. The "S" curve is a tool of great use for project tracing and monitoring, since it is known for each unit of time defined if what is applied of the expense is what it should be. On the other hand, it is the basis for applying the earned value management methodology, to determine arrears or advances in the schedule and budget, as well as to determine trends and forecasts of completion in time and cost.

One of the main advantages of this tool lies in the easy visualization of the project progress, so that both for the person in charge of the project, as well as for the superior to whom it is necessary to report periodically, it is very simple and clear to know which is the current situation or status of the project or work.

[20] It establishes that the Earned Value Management methodology (EVM) is, without a doubt, one of the simplest and most widely disseminated techniques for project monitoring and control, as well as for managing its performance. However, most studies on EVM extensions and applications concentrate on improving the final cost and duration estimates instead of improving the use of the Planned Value (PV) to predict the value gained and the actual cost value.

The study carried out by [21] proposes a simple modeling method to improve the predictive power of PV before executing a project. Through this modeling method, this study develops EV and AC prediction models for four projects of a case study. Validation of prediction outside the sample using the mean absolute percentage error (MAPE) showed that the proposed method improves prediction accuracy by an average of $23.66 \%$ and $17.39 \%$ for EV and AC respectively. This improvement in the predictive power of PV before project execution provides management with more reliable predictive information about $\mathrm{EV}$ and $\mathrm{AC}$ performance, allowing for effective proactive action to ensure favorable performance outcomes.

In the same sense [22] it establishes that the ability to develop a reliable "Estimation to the conclusion" from the project first stage execution is essential for proactive project management. In order to achieve this objective, they present a model to formulate estimates at the end that is integrated through a Bayesian approach with three sources of knowledge: the experts opinions, the previous projects data and the current performance of the project in course which were applied to three Oil and Gas projects in order to forecast their final duration and cost. The results obtained show a greater accuracy of the Bayesian model compared to the traditional methodology of Earned Value Management (EVM). 
There are other developments in this regard such as the EDM (Earned Duration Management) described in [23], which establishes that the concept of monitoring and control of programming as one of the most important functions of the project and the program management has not been exploited completely. A possible explanation could be the predominance of the Earned Value Management System. EVM was originally developed as a cost control and management tool that was extended to follow the schedule as well. EVM and its derivatives as management of the chronogram gained use the cost as an agent to measure the schedule performance and thus control the project duration. Although there is a correlation between the schedule, the cost, the quality and the scope of a project, the cost to control the duration has proven to be misleading. In contrast to the Earned Value and Earned Schedule, the authors developed Earned Duration Management (EDM), in which they have decoupled the timeline and cost performance measures and developed a series of indexes to measure the progress and performance of the schedule and cost, as well as the effectiveness and plan efficiency at any level of the project. These new indexes are easy to understand, have wider applications and can be used by contractors, customers and programming offices to evaluate and measure the performance of programming. The recently developed performance measures of duration are based on the schedule and can be used to forecast the end date of the project.

\section{G. Projects Closure}

One of the main tools for projects closing are closing audits, which highlight team members and organizations change and improvements.

[13] establishes that continuous improvement and organizational learning are a condition for competitiveness and for this the project audits have shown drastic improvements, making audits an important tool for projects closure.

The most used project management methodologies in the world give special relevance to the lessons learned. Thus the lessons learned are defined [5] as the documented experiences that can be used to improve the projects future management, programs and portfolios. In the same way [1] it defines them as the knowledge acquired during a project which shows how project events were addressed or should be addressed, in order to improve future performance.

The lessons learned are defined by [24] as the knowledge acquired about a process or several experiences that is constructed through reflection and critical analysis of results that could have had an impact on failure or success and that can be replicated in others projects.

Finally, it is important to mention other tools related to the projects closure, such as the personnel evaluation, the ExPost evaluation and the CheckList or the project closure checklist.

\section{H. Data collection instrument}

The fieldwork of this research was based on a survey applied to a representative sample of the construction sector and through random sampling the questionnaire was applied to the project managers of those companies. The Survey was structured with 37 questions and was titled "Measurement of
Project Management Tools and Techniques (T\&T) Usage in Building Sector Companies in Cartagena City". The purpose of the instrument was to compile the information that allowed to know project management tools and techniques usage in a general way presented by construction companies of Cartagena city.

\section{RESULTS}

The results analysis main findings are presented below: $45.5 \%$ of the companies occupy between 36 and 100 employees and $27.3 \%$ have more than 100 employees.

The executed contracts average value reaches considerable amounts (more than 10,000 million for $18.2 \%$ and between 5,001 and 10,000 million for the rest). Most of the companies, $40.9 \%$ of them build in all socioeconomic strata, $27.3 \%$ in lowincome housing, $22.7 \%$ in strata 5 and 6 and $5.6 \%$. in strata 3 and 4.

Study findings by process group are detailed below.

\section{A. Project Start Process}

$22.7 \%$ claim not to have a methodology to manage their projects and only a small percentage, $13 \%$, state they use PRINCE2, APM, PMI, or ISO 21500 and 64\% say they have adopted their own methodology that deviates from international standards.

It is also important to emphasize that almost half of the companies do not have project offices that can give support and follow-up to the projects, as well as facilitate proper use of tools and techniques.

From the certifications point of view it was determined that there is a low level of maturity in this field, since only $32 \%$ of the companies have certified personnel in project management, although there are certified people in specific areas of construction, not being certified implies that there is no validated knowledge regarding use of tools and techniques.

On the other hand, prioritization and selection of construction projects of these companies is mainly done with profitability criteria, more than $77 \%$.

Companies have different types of organizational structures, although the vast majority are matrix. 36\% functional, 50\% matrix where the functional and project-based are combined and $14 \%$ have a projected structure.

The key start-up tools used by these companies are the contract and the initial act, where one group privileges the contract $68.2 \%$ and in the other group the Works Start Act predominates $59.1 \%$.

Another of the findings detected in the start-up phase is that stakeholder management is very weak in companies and more than $50 \%$ does not do this management. Some use stakeholder registration, stakeholder assessment evaluation matrix, Incident Registry and Information Management systems.

\section{B. Planning Process}

Regarding planning, we can see the great importance that construction sector gives to aspects such as cost, time and scope with the highest response percentages (more than $86 \%$ ), which is in accordance with the triple restriction of project management and leaving aside issues such as Risks, 
Stakeholders and Communications with the lowest rates (less than $50 \%$ ).

The way in which companies define the project scope is done through the terms of the contracts reference. The EDT or WBS is only executed in $18.2 \%$ of the companies, which is a great shortcoming taking into account the great theoretical and practical importance that is given to this tool in most of the recognized standards and methodologies.

In relation to the estimates of time and cost, almost all companies make their estimates according to recognized practices, the estimates of time and cost are based on the PERT method, use of the estimate the three values is almost zero.

Similarly, time planning techniques such as critical chain, Crashing and fast-tracking (less than $10 \%$ for each of them) are very little used. The use of the project network (activities, sequence, resources) is very common at this stage, with $72.7 \%$. Traditional methods such as critical route and precedence diagramming are used, although on a smaller scale $(36.4 \%$ and $27.3 \%$ respectively)

From the human resources planning it is established that Organizational Diagram is used in $77.3 \%$ of the companies and only $31.8 \%$ uses the RACI matrix.

Personnel selection processes are carried out and there are policies to improve the performance of human resources. Most of the time it is done through prior assignment $(90.9 \%)$ and the performance is achieved with basic rules $(81.8 \%)$.

The application of techniques and tools for risk management is very weak, only in $54.5 \%$ of the cases a risk register is kept, $36.4 \%$ use the probability and impact matrix, the strategy to respond to risks are almost nil and in $31.8 \%$ of the companies there is no risk plan.

Root cause analysis and SWOT analysis are very scarce (22.7\% of companies use it). However, although there is no formal risk plan, some are identified in their vast majority technical and financial risks (72.7\%). Companies do not follow up on risks and the few plans that exist are made according to bidding and hiring requirements.

Finally, to close the planning process, budgets are made based on management reserves $(81 \%)$, few companies include the contingency reserve, which again correlates with the low level of risk analysis in these It is done.

\section{Execution Process}

Within the acquisitions management, strength of requests use for proposals $(77.3 \%)$ and negotiation $(63.6 \%)$, is under the use of activities such as conference of bidders (18.2\%), claims management $(9.1 \%)$ and contract change control systems $(9.1 \%)$.

The most frequent type of contract is the fixed price contract $(90.9 \%)$, consistent with the fact that scope is widely known and agreed at the beginning of the projects.

Interactive communication is the most used in construction projects $(90.9 \%)$ due to the high degree of work that is done daily and the large number of interested parties in this class projects. The PMIS information management systems (9.1\%) are still of low maturity, as is the Pull type information (9.1\%).

Regarding quality of the projects, $63.6 \%$ of the companies use the verification sheets or Check List and $86.4 \%$ use the inspections. Quality tools such as Histograms, Pareto diagrams, scatter diagrams are used by less than $27.3 \%$ of companies. Likewise, statistical sampling $(13.6 \%)$ and process analysis $(45.5 \%)$ are little used for quality control.

To plan and monitor projects, most companies use Microsoft Office and Microsoft Project, 90.9\% and 72.7\% respectively. Although most use a specialized tool for projects, it is also true that they use Excel and Word to make reports and calculate indicators and progress.

The use of lessons learned is low, only $27.3 \%$ use this technique. There is also a deficiency in the use of the change control system $31.8 \%$ and in performance reports $27.3 \%$. However, if you highlight the fact that $86.4 \%$ of companies give special importance to follow-up meetings, to monthly reports $81.8 \%$ and to weekly reports $50 \%$.

\section{Monitoring and Control Process}

In relation to the Monitoring and Control process, it was found that the projects are basically evaluated with the followup techniques of milestones $63.6 \%$, Curve S 54.5\% and Gantt Chart $50 \%$.

Companies still do not use the Earned Value Management, only $27.3 \%$ of companies use this method widely recognized worldwide, which is very useful for monitoring and control.

The value earned is one of the most important methods of project management and it is observed that of the 6 companies that claim to use this method, they are not doing it completely and integrally by using all their variables, since while some of they use the indexes of variations as $\mathrm{SV}, \mathrm{CV}, 13.6 \%$, others only use the indicators to make ETC forecasts, EAC 13.6\%.

Finally, for this process, it is important to highlight the tools that companies use to manage safety and the environment. These companies have strengths in environmental management plans $81.8 \%$, meetings of safety and environment $77.3 \%$ and work permits $68.2 \%$ among others. However, they have shortcomings in security metrics $18.2 \%$, emergency response plan $36.4 \%$ and drills and training $40.9 \%$ among others.

\section{E. Closing process}

For closing processes, these companies focus on financial and administrative aspects $77.3 \%$ and $63.6 \%$ respectively. To resolve the claims, companies prefer to negotiate, $72 \%$, and mediation, $45 \%$, before the litigation, $9.1 \%$, or to be solved by someone independent neutral, 9,1\%. For this process, companies omit the team members evaluations and the lessons learned, $31.8 \%$.

\section{RECOMMENDATIONS GUIDE}

Research prioritizes the main tools and techniques that should be used by the construction companies of Cartagena city making use of the findings between the state of art and diagnosis made. As a result of the research, a user-friendly teaching guide was designed with clear instructions on how and when to use each technique or tool. A total of 20 tools were chosen that are considered the most representative and that in their great majority represent a weakness of the sector, since the activity profile is of vital importance for productivity. Many of these tools are not well known and some must be implemented 
urgently in companies since their applicability internationally has shown efficiency in project management.

To make the guide in a didactic way, a technical sheet was designed for each selected tool. Thus, each was captured in a vertical list of tables which contains four parts; the first box called "Description" contains the basic definition of the tool or technique, what is its main objective and its main characteristics, the second box called "Content" has reflected the use that is given to the tool, how it is developed or built and which are its main components, the third table called "Recommendations" establishes specific guidelines for the construction sector, issues to be taken into account, specific vocabulary and recommendations for this sector and finally in the fourth box called "Reference" it is defined where each tool should rest, who is responsible for carrying it out or filling it out and in what bibliography it can be deepened in it. The following are the recommended $\mathrm{T} \& \mathrm{~T}$ for the construction sector of Cartagena city, which according to the research are relevant to improve the projects success:

- Project Charter

- Stakeholder Registration

- WBS (Work Breakdown Structure)

- Time and Cost Estimation Techniques

- Project Network

- Critical Path Method

- PERT

- OBS (Organizational Breakdown Structure)

- RACI Matrix

- Risk Register

- Communications Matrix

- Quality Tools

- Hiring Matrix

- Monthly / Weekly Reports

- "S" Curve

-Gantt diagram

- Livestock Value Technique

- Change Control System

- Project Performance Evaluation

-Learned lessons.

\section{CONCLUSIONS}

The analysis carried out in this investigation confirmed locally in the construction companies, that the failures rate projects have today is high, since only $36.4 \%$ of the Project managers claim to be successful in $80 \%$ of the projects or more, what deserves to continue working from the theoreticalpractical part in the assimilation and appropriation of good practices to manage the projects. It is essential that companies begin to train their teams and managers in careers and project management certifications in order to give appropriate use to different techniques and tools offered by the discipline in order to increase rate success in coming years. of your projects.

The diagnosis made in the construction companies of Cartagena city yielded very positive results in terms of some techniques and tools usage such as: cost and time estimation techniques, project network, management reserves, financial closures, follow-up with diagrams of Gantt, checklists, organization charts, contracting and negotiation tools, and specific to the sector such as those related to industrial safety and the environment. In the same sense it was evident that the management plans that are carried out in these companies have great strength in the areas of costs, time and scope following the traditional approach of the triple restriction.

However, this research work also revealed very poor results in terms of tools and techniques application and are widely recognized as good practices worldwide such as: Project Charter, EDT, RACI Matrix, Contingency Reserves, tools to manage stakeholders and risks. Likewise, it was possible to detect that very few companies (less than 32\%) have certified personnel in project management, which translates into a disadvantage when correctly applying the tools.

The diagnosis made also gave guidelines for a simple guide, basic and didactic, in which project managers can start consulting and apply each one of them by means of the characteristics of the technical sheets prepared for each one. It is important that project managers deepen these and other tools to begin to mature the discipline of project management in their organizations. In each tool of the guide, several reference references are detailed where the elaborated concepts can be deepened in more detail.

It is recommended to continue with the study of application of techniques and tools at the regional and national levels and in different sectors to the construction, to make multidisciplinary comparisons and to be able to extend the guide and the recommendations with the objective that the project managers can mature in the application of these and make your projects more successful.

Finally, it is recommended to carry out similar studies seeking to apply a survey and make diagnoses in terms of proper methodologies for planning and execution of projects. It is important not only to stay with the tools and techniques but to develop strong methodologies taking into account that currently almost half of the companies claimed to have their own methodologies without fully relying on any particular standard or methodology, which shows flaws when applying the tools and techniques and therefore the processes and activities of project management within their projects.

\section{REFERENCES}

[1] Institute, Project Management; A Guide to the Project Management Body of Knowledge (PMBOK), Sexta ed., Pensylvania: Project Management Institute, 2017.

[2] CAMACOL (Cámara Colombiana de la Construcción), «Informe de Coyuntura económica,» Camacol Regional Bolívar, Cartagena de Indias, 2016.

[3] Pulse of the Profession, «El impacto estratégico de los proyectos. Identifique los beneficios del Negocio,» Project Management Institute, 2016.

[4] K. Bowen, Manual de Dirección de Proyectos, Harvard Business School, 2002. 
[5] Association For Project Management, APM Body Of Knowledge, Sexta ed., Guckinghamshire: Association For Project Management, Inc., 2012.

[6] J. P. Clements, J. Gido y R. Baker, Administración Exitosa de Proyectos, Sexta ed., Ciudad de México: CENGAGE Learning, 2018.

[7] P. Morris, «Research and the future of project Management,» International Journal of Managing Projects in Business, vol. 3, $\mathrm{n}^{\mathrm{o}}$ 1, pp. 139-146, 2010.

[8] F. David, Strategic Management: A Competitive Advantage Approach Concepts, 14th ed., F. M. University, Ed., Florence, South Carolina: Pearson, 2013.

[9] H. Kerzner, Strategic Planning for Project Management Usign a Project Management Maturity Model, New York: John Wiley \& Sons, Inc, 2001.

[10] C. Gray y E. Larson, Project Management: The Managerial Process, 5th ed., New York: McGrawHill/Irwin, 2011.

[11] D. Buchanan y D. Boddy, The expertise of the change agent: public performance and backstage activity, Prentice-Hall, 1992.

[12] E. L. Field, Problem solving in government project management, MIT, Ed., Cambridge, Massachusetts, 1966.

[13] J. K. Pinto, Project Management: Achieving Competitive Advantage, 4th ed., P. S. University, Ed., Pearson, 2016.

[14] W. Duncan, «Scoping out a scope statement,» $P M$ Network, p. 47-48, 1994.

[15] G. D. Lavold, D. I. Cleland y W. R. King, Developing and Using the Work Breakdown Structure. Project Management Handbook, Segunda ed., New York: John Wiley \& Sons, 1998, p. 302.

[16] P. Falster, J. Pinto, A. Rolstadås y R. Venkataraman, «Project Decision Chain,» Project Management Journal, vol. 46, no 4, p. 6-19, 2015.

[17] L. Raymond y F. Bergeron, «Project management information systems,» vol. 26, p. 213-220, 2008.

[18] B. W. Tuckman y M. A. C. Jensen, «Stages of SmallGroup Development,» Revisited Group \& Organization Studies, vol. 4, nº 2, pp. 419-427, 1977.

[19] W.-H. L. Liu y J. A. Cross, «A comprehensive model of project team technical performance,» International Journal of Project Management, vol. 34, p. 1150-1166, 2016.

[20] L. Willems y M. Vanhoucke, «Classification of articles and journals on project control and earned value management,» International Journal of Project Management, vol. 33, pp. 1610-1634, 2015.

[21] H. L. Chen, W. T. Chen y Y. L. Lin, «Earned value project management: Improving the predictive,» International Journal of Project Management, vol. 34, nº 1, 2016.
[22] F. Caron, F. Ruggeri y B. Pierini, «A Bayesian approach to improving estimate to complete,» International Journal of Project Management, vol. 34, no 8, 2016.

[23] H. Kamooshi y H. Golafshani, «EDM: Earned Duration Management, a new approach to schedule performance managements and measurement, International Journal of Project Management, vol. 32, pp. 1019-1041, 2014.

[24] E. Luna y L. Rodríguez, «Lecciones aprendidas y Buenas Prácticas,» Sector de Conocimiento y Aprendizaje. Banco Interamericano de desarrollo, Marzo 20011. 